\title{
Correction to: Agriculture induces isotopic shifts and niche contraction in Horned Larks (Eremophila alpestris) of the Colorado Desert
}

\author{
Nicholas A. Mason ${ }^{1,2}$ (1) $\cdot$ Philip Unitt ${ }^{3} \cdot$ Jed P. Sparks ${ }^{1}$
}

Published online: 3 April 2021

(c) Deutsche Ornithologen-Gesellschaft e.V. 2021

Correction to: Journal of Ornithology

https://doi.org/10.1007/s10336-020-01834-0

In the original publication of the article, article title was published with an error.

The German title was published along with the English title which does not come under journal style.

The original article has been updated with the correct title.

Publisher's Note Springer Nature remains neutral with regard to jurisdictional claims in published maps and institutional affiliations.

The original article can be found online at https://doi.org/10.1007/ s10336-020-01834-0.

Nicholas A. Mason

mason@1su.edu

1 Department of Ecology and Evolutionary Biology, Cornell University, Corson Hall, Ithaca, NY 14853, USA

2 Museum of Natural Science and Department of Biological Sciences, Louisiana State University, Baton Rouge, LA 70803, USA

3 San Diego Natural History Museum, P.O. Box 121390, San Diego, CA 92112, USA 